Revista de la red interuniversitaria de estudios sobre las literaturas rioplatenses contemporáneas en Francia

$11 \mid 2014$

De niños e infancias

\title{
Escritora Infante de la Marina Mercante
}

\section{Pola Oloixarac}

\section{OpenEdition}

Journals

Edición electrónica

URL: http://journals.openedition.org/lirico/1839

DOI: $10.4000 /$ lirico.1839

ISSN: 2262-8339

Editor

Réseau interuniversitaire d'étude des littératures contemporaines du Río de la Plata

Referencia electrónica

Pola Oloixarac, «Escritora Infante de la Marina Mercante », Cuadernos LIRICO [En línea], 11 | 2014

Puesto en línea el 01 diciembre 2014, consultado el 04 mayo 2019. URL : http:// journals.openedition.org/lirico/1839; DOI : 10.4000/lirico.1839

Este documento fue generado automáticamente el 4 mayo 2019.

\section{(c) (1) $\Theta \Theta$}

Cuadernos LIRICO está distribuido bajo una Licencia Creative Commons Atribución-NoComercialSinDerivar 4.0 Internacional. 


\title{
Escritora Infante de la Marina Mercante
}

\author{
Pola Oloixarac
}

\section{NOTA DEL EDITOR}

Pola Oloixarac es la autora de la novela Las teorías salvajes (Entropía, 2008) y del libretto de la ópera Hércules en el Mato Grosso (2014) encargo del Centro de Experimentación del Teatro Colón. Colabora con artículos para The New York Times y edita Buenos Aires Review. Su novela Las constelaciones oscuras se publica en 2015. 


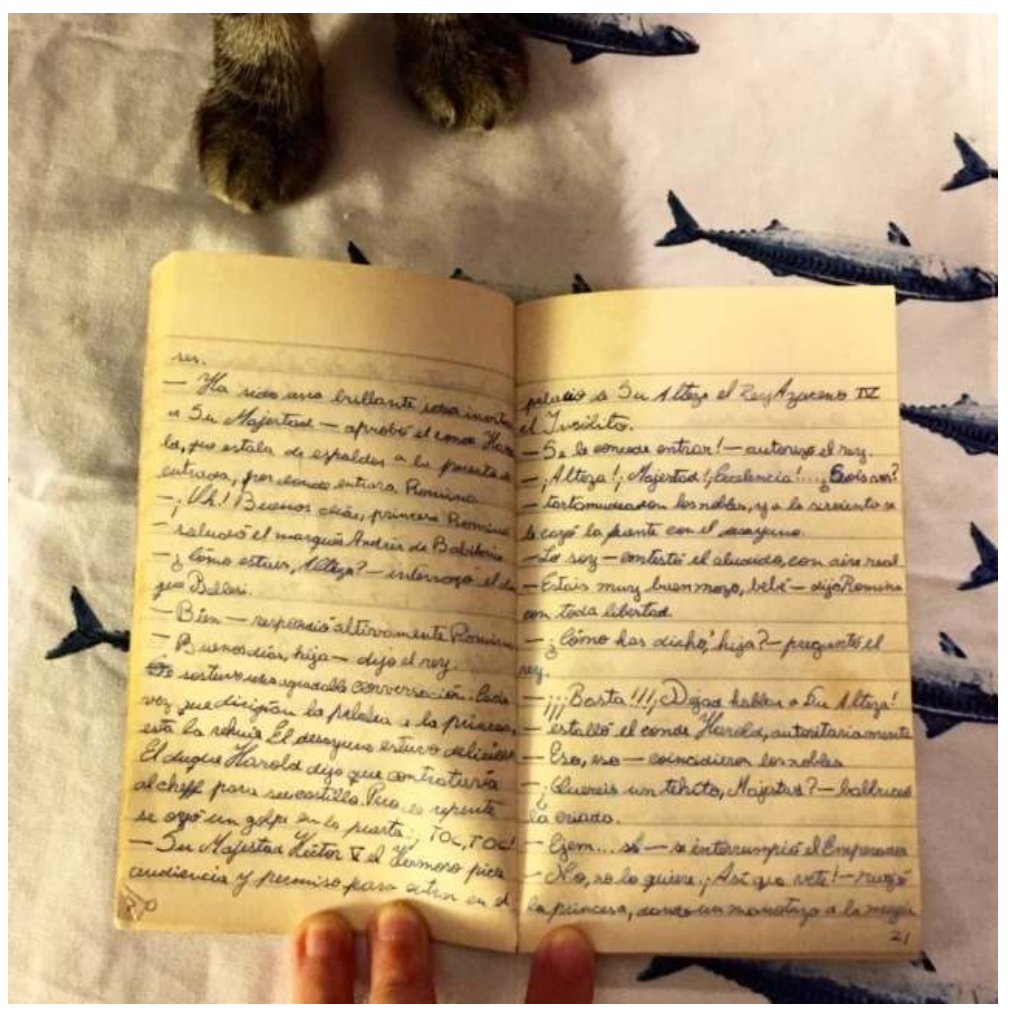

Empecé a escribir a los siete años en unas libretitas negras de ELMA, la Empresa Líneas Marítimas Argentinas. También nací en el sanatorio de ELMA; ELMA dejó de existir a principios de los años 90, desintegrada durante el primer mandato de Carlos Menem. Yo viajé en esos barcos gigantescos, donde mi papá era Jefe de Máquinas, y en esos viajes cruzando el Atlántico escribí mi primera novela.

Mi primera historia, en una de estas libretitas, era una fantasía arábiga: Un rey crudelísimo, Azuceno IV, apodado el Asesino, tenía una hija horrenda, Romina, que se dedicaba a elucubrar torturas inverosímiles. Rosa, la heroína, era una deliciosa jovencita que formaba parte de las Odaliscas del reino y quedaba enamorada, con sólo verlo, de un noble viajero que venía a solicitar un favor de Azuceno, conquistando a su pesar a la horrenda Romina; para encontrarse con su interés romántico, para espiarlo, Rosa se escondía primero en unos cortinados y luego descendía a unos túneles. En mi imaginación los túneles eran muy angostos, y para describir el pasaje de mi heroína por los túneles puse que ella pasaba contoneándose, porque me sonó adecuado. Cuando lo mostré, ese pasaje fue objeto de risas adultas. ¿Qué se supone que hacía mi heroína, "contoneándose", en un túnel ? Entendí que el verbo distaba de perfecto ; de todos modos, la presunción del doble sentido me pareció de una vulgaridad supina y me ofendí. No pude terminar esa historia.

3 Decidí no mostrar a nadie más mis obras (entre las que se contaban "Manual para la vida perfecta" y "Verónica"). Ya las leerían cuando fuera archifamosa. Había tomado un seudónimo, Cora Málaga, con el que firmaba mis libros. Había decidido que sería escritora; pronto decidí que jamás escribiría historias autobiográficas. No sé bien de dónde saqué esa aversión. Recuerdo también que quería ser escritor y no escritora, aunque yo ya era Cora Málaga, pero no importaba : era una declaración de principios de algún tipo, que se vinculaba de alguna manera con la aversión a la cuestión autobiográfica. Enderezaba la mirada (tenía estrabismo) y mantenía esta idea con cierta 
audaz seguridad, pero sólo recuerdo vagamente el argumento : que el valor debía estar en relación a la imaginación, que la persona puntual que escribe es secundaria. Esto me hace pensar que ya había entrado en contacto con lo borgiano, aún sin haber leído a Borges ${ }^{1}$. Escribí mi primera novela en el verano de los ocho, y mi ser de pluma fantasioso debió nacer cuando cursaba cuarto grado.

Se intitulaba "Días de Revolución" y comienza : "Un par de soldados franceses se abrían paso por la maleza que abundaba por los alrededores. Los dos hombres vigilaban la selva : había estallado la revolución. París era ya un nido de ratas." Un soldado herido era recogido por un sirviente que patrullaba el bosque lindante al castillo, temerosos de la llegada de los revolucionarios. Un dramón: el jefe de los enemigos, el holandés van Stuyvesant, tiene una doble agenda para capturar el castillo y una vez que consigue la rendición traiciona a los revolucionarios franceses. Empezaba con un argumento romántico, que después encontraría en "El incendio y las vísperas" de Beatriz Guido : el joven soldado herido curado por la muchacha de alcurnia, hija de su enemigo ideológico. Por lo demás, mi heroína se llamaba Eugénie, la versión francesa de mi mejor amiga de la escuela; y el resto de los personajes femeninos (excepto de Madame Olimpia, la madre y señora del castillo) se llamaba como mis amiguitas del colegio. Mi próxima novela, "Verónica", sería un libro protagonizado por mi amiguita Verónica a la manera de la saga "Katy" de Susan Coolidge y esos libros victorianos donde se aprenden el valor de la nobleza, la valía personal y la amistad. Evidentemente, mis relaciones con la ideología trastabillaron desde el comienzo : la autobiografía se colaba en todas partes. (Esto que escribo también es para una amiga.) Quizás, lo que quería evitar -lo que me parecía nefasto, y me sigue pareciendo tremebundo- era contar lo que hacía todos los días. En mi casa no se tomaba mate ; pero si lo hubiéramos hecho, jamás hubiera metido una pava y un calentador en uno de mis escritos. Mis hábitos pueden haberse modificado, puedo tomar mate ; pero me mantengo fiel a ese credo de mis ocho años, a esa pava elidida.

Escribí mi primera novela con una Parker de tinta azul y la pasé toda en mi olivetti naranja portátil. Tenía mi escritorio en el camarote, que compartía con mi hermana y estaba destinado al Armador, ausente en ese viaje. Además de escribir, el barco era un mundo lleno de sucesos maravillosos. Mi hermana y yo, en tanto hijas de un Oficial de Máquinas (el Jefe), comíamos en el comedor de Oficiales De Máquinas y Cubierta, donde nos atendían los Mozos de Oficiales y había un menú con entrada, plato principal y postre ; nuestros camarotes estaban por sobre la línea de cubierta. Jugábamos con los dos niños del $1^{\circ}$ oficial de Cubierta pero nuestros amigos preferidos eran el hijo del electricista y la hija del cocinero, que comían en la zona de Maestranza, que tenía su propio Mozo de Maestranza ; más abajo había otro comedor, que era Marinería (por un tiempo me pregunté, ¿quién atendía a los de Marinería? Quizás eran avanzados y había buffet). Vastas zonas del barco estaban teóricamente prohibidas para niñas como nosotras, pero nuestros amigos era nuestros capitanes de exploración: la hija del cocinero tenía la llave de los enormes arsenales de comida, el magno frigorífico donde guardaban los kilos y kilos de helado. Ahí nos metíamos como ratas con nuestras cucharitas. Mi mamá, que en tierra nos peinaba el pelo tirante y nos vestía iguales, no podía seguirnos en nuestras aventuras. De vez en cuando mi papá nos llevaba a la Máquina, que recuerdo totalmente surreal. Había que abandonar oficiales y descender a través de Maestranza, ponerse el casco y prepararse para bajar a lo infernal. Un laberinto de escaleras de metal, denso de calor y de ruido ensordecedor, y debajo, central, el corazón del poderío, la bomba del barco latiendo en la oscuridad. Yo insistía en no usar 
orejeras, porque el temblor me estremecía en un miedo delicioso. Los subordinados de mi padre subían y bajaban las escaleritas con mamelucos manchados de negro; en medio del clamor y la oscuridad nos descubrían sus ojos amigos, sus dientes blancos en una sonrisa y había ínclita una pequeña reverencia, un regalo reservado para las niñas aventureras que se animaban a visitar la Máquina.

6 Así pasábamos meses, recorriendo las costas del Pacífico y surcando el Atlántico, cruzando el Mediterráneo o varados para eludir la cola de un huracán. El barco interior era un mundo que yo conocía muy bien, porque era versada en los Tigres de Mompracem de Emilio Salgari, uno de mis grandes favoritos. Continuidad de los barcos : cruzábamos el océano en el barco, nos seguían los peces voladores y en cualquier momento podía desatarse una tormenta terrible que ponía la línea del horizonte al revés en el ojo de buey, Sandokan surfeando a lo lejos, las chalupas enemigas aproximándose, Yáñez de timonel en plena destrucción del cielo. Pero también pasaban otras cosas de las yo no sabía nada.

7 Una noche nos quedamos en el gran arsenal de Galletitas; habíamos atracado en algún puerto. Teníamos tantas aventuras en el barco que perdíamos interés en lo que había en tierra ; además, en tierra nos obligaban a pasear o mi mamá nos metía rápidamente en un hotel cinco estrellas y nos dejaba a merced de las "actividades para niños", tedios infames fundados en la indolencia y la mímesis. Por el ojo de buey espiábamos el puerto a oscuras. Era medianoche y habían desplegado la planchada ; algunos autos, un grupo de hombres y mujeres hablando en el muelle; mujeres escalando los escalones precarios, ayudadas por algunos hombres. No reconocíamos a nadie; ¿sería la gente de Marinería ? El hijo del electricista y la hija del cocinero abrieron el cancel y gritaron ¡Prostitutas! y nosotras gritamos también, aunque no sabíamos qué era. Ellas se dieron vuelta hacia nosotros y dejaron de reírse. La palabra me parecía rarísima : "prosti" me sonaba a remedio.

Había solo dos mujeres oficiales en la tripulación : la Comisario y la Radio. La Radio era la encargada de la telefonía ; para hablar con tierra había que hablar como con walkie talkies, decir cosas como cambio y fuera. La Comisario era una administradora de todas las compras del barco, llevaba la contaduría y rendía los papeles al llegar a tierra. Las carreras de Máquinas y Cubierta no contemplaban la inserción de mujeres; como tampoco Marinería. (Años después, las mujeres pudieron entrar en Cubierta, para hacer la carrera de Capitán ; pero para entonces la Marina Mercante Argentina ya no existía, la flota nacional había sido desguasada, con astilleros y barcos enteros vendiéndose por céntimos, cien mil dólares).

9 La Radio tenía el pelo rubio lacio ; la Comisario tenía el pelo con permanente rojizo y los ojos sombreados de celeste, como escapada de las Gatitas y Ratones de Porcel. Eran las verdaderas reinas del barco. Eran las recipientes de una serie de galanterías que ahora serían totalmente incorrectas, bromas que ya no pueden existir en voz alta; dueñas y señoras de su propio sentido epocal, ellas iban tranquilísimas por los laberintos de Oficiales y explotaban fuertemente sus encantos, sobre todo la Comisario. Siempre tenía la camisa blanca entreabierta, la falda azul (los colores de los oficiales) muy ceñida al cuerpo. Una tarde íbamos con mi papá por los laberintos de camarotes : la Comisario se apareció y cruzó una pierna seductora, con su taco azul marino, para no dejarnos pasar. Mi papá le dijo que no embromara y yo salté la valla de su pierna y atrás quedó Escila derrotada, a llorar con Caribdis. En una fiesta de Bautismo por haber cruzado el Ecuador (el Capitán, vestido de Neptuno, decía palabras inmortales mientras te llenaban la cabeza de engrudo), yo quería que la Comisario fuera la novia de nuestro amigo de la Máquina, el 
$3^{\circ}$ oficial de Cubierta, Chapu, pero ella se fue con el rubio $2^{\circ}$ de Cubierta al que le decíamos Donovan porque era igual al de Invasión Extraterrestre. El $3^{\circ}$ de Cubierta, en cambio, me hacía acordar a Yáñez. Después supe que no lo hacía por bromear, que era tartamudo de verdad; había estado en el hundimiento del General Belgrano en Malvinas, había visto morir a sus compañeros y había logrado salvar su vida.

Una tarde en tierra, cuando terminé uno de Salgari (acaso "Los Dos Tigres") me quedé dormida y soñé que la cubierta estaba llena de riñones y vísceras humanas. Era un día magnífico de sol en ultramar : yo salía de mi camarote y Sandokan mismo aparecía y me daba la bienvenida como a una camarada, como la capitana del Yucatán. Yáñez estaba en la proa, no lo veía ; un plan era urdido ; yo no sabía si las vísceras eran por la cantidad de muertos de la batalla anterior. Cuando desperté y me di cuenta de lo ocurrido, me sentí desfallecer. Me di cuenta de que iba a tener que vivir afuera del libro para siempre, lo que era repugnante y horroroso, y lloré con amargura. Sandokan viviría en el libro y yo había quedado afuera. Era como si su nave hubiera partido y me hubieran dejado sola en tierra.

Mi mamá de anteojos y tacos altos sobre la brea del puerto de Buenos Aires, ataviada elegantísima para ver llegar a mi papá en el barco. El largo proceso de maniobra, con dos alíscafos ayudando el concierto de los marineros para equilibrar el barco, poner al enorme mamut marino en posición ; mi hermana y yo en el muelle de punta en blanco, el pelo atado tirante. Al puerto de Buenos Aires se entraba por la calle Cangallo ; había una barrera y en general te revisaban el auto. Es el puerto que aparece en las películas de Pino Solanas y Subiela; luego volví durante el primer año del Colegio Nacional de Buenos Aires, a jugar al hockey. Ese mundo no existe más. Para cuando yo empecé a escribir con idea concreta de dedicarme a mi sueño de niña, Argentina había dejado de tener ELMA y una flota nacional. Durante los últimos peronismos Argentina no sólo perdió el ultramar, si no también el cabotaje y el río; las flotas paraguaya y boliviana la superan con comodidad. Así, con la fuerza idiota del Estado en viento en popa, ahora la supremacía del Mar Argentino pertenece a la internacional Maersk, que navega con bandera y tripulación inglesas. Como Sandokan, muchas veces los argentinos van de incognito en sus propios mares infestados de otro imperio; registran los barcos bajo banderas liberianas, panameñas. Larvatus prodeo, me paseo enmascarado: el arte de la navegación implica cosas fundamentales para quien escribe, como saber hacerse invisible, y rondar de cerca la Máquina.

\section{NOTAS}

1. Cuando estaba en tierra (como se denomina la vida en el continente en la jerga de los barcos) leía, además de los libros que me interesaban, el suplemento cultural de la Nación y el "Ciencia y Técnica” de Clarín. Guardaba los artículos que me gustaban, especialmente sobre dinosaurios y la exploración estelar, y los organizaba en carpetitas fechadas. Sospecho que esa llegada del precepto borgiano venía de la lectura de esos suplementos. 